\title{
Comparison between Thin-Layer Models and Non- Traditional Methods in the Modelling of Drying Kinetics of Crustacean Wastes
}

Thais Serra Martins ${ }^{1}$

https://orcid.org/0000-0003-2012-6789

\section{Thiago Sousa e Sousa ${ }^{1}$}

https://orcid.org/0000-0001-5063-1095

Victor Hugo Gomes Sales ${ }^{2}$

https://orcid.org/0000-0002-8994-6251

\author{
Maria da Gloria Almeida Bandeira ${ }^{3}$ \\ https://orcid.org/0000-0003-3083-4463
}

\author{
Diana Maria Cano Higuita ${ }^{1}$ \\ https://orcid.org/0000-0002-3948-7317 \\ Harvey Alexander Villa Vélez ${ }^{1 *}$ \\ https://orcid.org/0000-0003-2394-4939
}

${ }^{1}$ Federal University of Maranhão, Center of Exact Sciences and Technology, Department of Chemical Engineering, São Luís, Maranhão, Brazil; ²Federal Institute of Amapá, Department of Food Technology, Macapá, Amapá, Brazil; ${ }^{3}$ Federal University of Maranhão, Center of Exact Sciences and Technology, Department of Chemical Technology, São Luís, Maranhão, Brazil.

Editor-in-Chief: Alexandre Rasi Aoki

Associate Editor: Alexandre Rasi Aoki

Received: 2019.01.06; Accepted: 2021.03.09.

*Correspondence: e-mail: harvey.villa@ufma.br. Phone number: +55 (98) 32729263 (H.A.V.V.).

\section{HIGHLIGHTS}

- Drying kinetics of shrimp shell and crab exoskeleton were obtained experimentally

- The Page and Midilli models showed the best fitting results to simulate the experimental data

- Third-order models were obtained for both materials using the stepwise fit method

- The ANNs showed the best fitting performance to describe the experimental drying curves

- Modeling of the drying process can be simulated successfully by multivariable approaches.

Abstract: This research aims to compare the classical thin-layer models, stepwise fit regression method (SRG) and artificial neural networks (ANN) in the modelling of drying kinetics of shrimp shell and crab exoskeleton. Thus, drying curves were obtained using a convective dryer $(3.0 \mathrm{~m} / \mathrm{s})$ at temperatures of 30.45 and $60^{\circ} \mathrm{C}$. The results showed a decreasing tendency for the drying time as the temperature increased for both materials. Drying curves modelling of both materials showed fitted results with $R_{a d j>0.998}^{2}$ and $M R E<13.128 \%$ for some thin-layer models. On the other hand, by SRG a simple model could be obtained as a function of time and temperature, with the greatest accuracy being found in the modelling of experimental data of crab exoskeleton, with $M R E<10.149 \%$. Finally, the ANNs were employed successfully in the modelling of drying kinetics, showing high prediction quality with the trained recurrent ANN models.

Keywords: artificial neural network; crab exoskeleton; mathematical modelling; shrimp shell; statistical validation; stepwise fit regression. 


\section{INTRODUCTION}

Shrimp shell and crab exoskeleton are two crustacean wastes with great capacity for exploitation due to their high contents of chitin, chitosan and calcium carbonate [1,2]. Related studies such as the absorption of uranium in nitric solutions [3], removal of heavy metals [4], antimicrobial properties [5], biomineralization and polymorphism [6], and the protection against dental demineralization [2], amongst others, show the potential of their synthetized or natural compounds for application in food, chemical, material and pharmaceutical industries. However, the high molecular weight, low absorption of the minerals plus the high decomposition rate of these wastes, make it difficult to use them for such purposes.

A simple solution could be the application of dehydration technologies such as drying in order to guarantee a large amount of product during long periods of time. As already reported, drying is a unit operation that involves the mechanisms of mass and heat transfer [7], classic methods such as solar drying $[8,9]$, convective drying [10], and fluidized bed drying [11,12] are being studied up to the present day, as well as modern or combined methods such as microwave-drying [13], ultrasound assisted drying [14], pulse electric drying $[15,16]$ and freezing-drying $[17,18]$.

From the engineering point of view, the optimization and dimensioning of different drying equipment and methods require good accuracy of the constructed mathematical models based on their parameters. The control of the variables demands evaluation of the concatenated non-linear mass and heat properties. In this context, the mathematical modelling of the drying process is an important field of study that allows engineers to choose the most suitable method and process conditions in order to meet the needs and forecast the progress and the course of the process [19-21].

Models based on thin-layer theory describe the process as a sequence of probabilistic events with a solid theoretical basis stemming from physical principles. However, not all models present good performance, in many cases the description of drying rates depends on interrelated phenomena such as capillarity, diffusion and heat transport, in a complex way. In order to improve the performance of drying kinetic modelling, new methodologies, such as artificial neural networks (ANN) [11,18,22] and stepwise fit regression (SRG) [23-25] have increasingly gained attention as predictive tools, due to their unique advantages of being non-parametric models that can handle large amounts of data sets and are capable of doing nonlinear regression. Both methodologies produce simple models constructed with no need of detailed knowledge of the underlying system, and these special features have made them applicable in many fields of science. Thus, the present work aims to compare the use of thin-layer models, ANN and SRG to predict the drying kinetic curves of shrimp shell and crab exoskeleton at three temperature levels.

\section{MATERIAL AND METHODS}

\section{Raw material and sample preparation}

Fresh shrimp (Litopenaeus vannamei) and crab (Ucides cordatus) were acquired from a local market in the city of São Luís, Maranhão State, Brazil. After cleaning with enough water, shrimp shells and crab exoskeletons were separated from the meat manually and with use of a hammer, respectively. Each material was then reduced using a food processor (model Osterizer, Oster, USA), packed in hermetic plastic bags and stored at $-10^{\circ} \mathrm{C}$ in a freezer (model BVG24, Brastemp, Brazil) for subsequent testing. In order to obtain consistent results, the shrimp shells and crab exoskeletons were characterized chemically according with methods described by the AOAC official methods of analysis [26], as shown in Table 1.

Table 1. Proximate composition of shrimp shell and crab exoskeleton*.

\begin{tabular}{lcc}
\hline \multicolumn{1}{c}{ Composition } & Shrimp shell & Crab exoskeleton \\
\hline Water content (g/100 g, w.b.) & $6.702 \pm 0.374$ & $17.202 \pm 0.548$ \\
Protein (g/100 g, w.b.) & $39.107 \pm 1.791$ & $13.706 \pm 0.656$ \\
Lipid (g/100 g, w.b.) & $2.612 \pm 0.887$ & $1.777 \pm 0.593$ \\
Ash (g/100 g, w.b.) & $23.575 \pm 0.466$ & $58.638 \pm 0.271$ \\
Carbohydrate (g/100 g, w.b.)** $^{*}$ & $28.004 \pm 1.963$ & $8.677 \pm 1.120$ \\
\hline
\end{tabular}

* Mean and standard deviation of the triplicate. ${ }^{* *}$ Values calculated indirectly by subtraction of the other components. w.b: wet basis. 


\section{Experimental drying procedure}

The shrimp shell and crab exoskeleton particles were dried in a convective dryer (model PE14, Pardal, Brazil) at temperatures of 30,45 and $60^{\circ} \mathrm{C}$ and air velocity of $3.0 \mathrm{~m} / \mathrm{s}$. Each material was first placed on four cylindrical aluminum plates (diameter of $9.2 \mathrm{~cm}$ and height of $2.5 \mathrm{~cm}$ ) and positioned at the center of the dryer, where they were weighted using a semi-analytical balance (model UX220H, Shimadzu, Japan) after defined time intervals until reaching constant weight. The thickness of the material was measured randomly at different positions on each plate at the beginning and end of each experimental procedure. The relative humidity and temperature of the dryer were also monitored using a hygrometer (model INS-28, Instrusul, Brazil). The initial water content of each material was used to express the results of the drying kinetics as a function of water content on a dry weight basis "d.w.b.". Before each experiment, the samples were tempered at the experimental temperature for $60 \mathrm{~s}$, always covering each sample with a plastic film in order to avoid weight losses and the effects of convective heat transfer.

\section{Mathematical modelling}

In this study, thin-layer models, stepwise fit regression (SRG) and artificial neural networks (ANN) were applied to simulate the drying kinetic curves of shrimp shells and crab exoskeletons at different temperatures. For this, different functions from the Matlab® 7.1 Statistic Toolbox library (The MathWorks Inc., Natick, MA, USA) were used to obtain the best fitting results. The functions employed as well as the mathematical approach applied are described below.

\section{Thin-layer models}

The models of Weibull (Equation 1), Peleg (Equation 2), Henderson-Pabis (Equation 3), Logarithmic (Equation 4), Wang and Sing (Equation 5), Lewis (Equation 6), Page (Equation 7), Midilli (Equation 8), TwoTerms (Equation 9) and the Diffusion approach (Equation 10) [27-33] were adjusted to the experimental data by nonlinear regression using the "nlinfit" function, considering the robust fitting option. This function uses the Gauss-Newton algorithm with Levenberg-Marquardt modifications that iteratively reweigh the response values and re-compute the least-square fit of a non-linear model.

$$
\begin{aligned}
& X=X_{e}+\left(X_{0}-X_{e}\right) \exp \left(-\frac{t}{k_{1}}\right)^{k_{2}} \\
& X=X_{0}-\left(\frac{t}{k_{1}+k_{2} t}\right) \\
& X=X_{e}+\left(X_{0}-X_{e}\right) k_{2} \cdot \exp \left(-k_{2} t\right) \\
& X=X_{e}+\left(X_{0}-X_{e}\right) k_{1} \cdot \exp \left(-k_{2} t\right)+k_{3} \\
& X=X_{e}+\left(X_{0}-X_{e}\right) \cdot\left(k_{1} t^{2}+k_{2} t+1\right) \\
& X=X_{e}+\left(X_{0}-X_{e}\right) \exp \left(-k_{1} t\right) \\
& X=X_{e}+\left(X_{0}-X_{e}\right) \exp \left(-k_{1} t^{k_{2}}\right) \\
& X=X_{e}+\left(X_{0}-X_{e}\right) \exp \left(-k_{1} t^{k_{2}}\right)+k_{3} t \\
& X=X_{e}+\left(X_{0}-X_{e}\right)\left(k_{1} \exp \left(-k_{2} t\right)+k_{3} \exp \left(-k_{4} t\right)\right) \\
& X=X_{e}+\left(X_{0}-X_{e}\right) k_{1} \exp \left(-k_{2} t\right)+\left(1-k_{1}\right) \exp \left(-k_{2}\left(k_{3} t\right)\right)
\end{aligned}
$$

Where $X$ is the moisture content ( $\mathrm{kg} / \mathrm{kg}, \mathrm{d} . b.), X_{e}$ is the equilibrium moisture content $(\mathrm{kg} / \mathrm{kg}, \mathrm{d} . \mathrm{b}),. X_{o}$ is the initial moisture content (kg/kg, d.b.), $t$ is the time (s), and $k_{1}, k_{2}, k_{3}$ and $k_{4}$ are the drying constants (s; $\mathrm{s}^{-1}$; dimensionless).

\section{Stepwise fit regression}

SRG was employed combining the factors of temperature and drying time through the function "stepwisefit", which uses the best combination of the factors based on adding or deleting the model terms being evaluated from a significance test $(p<0.05)$. Thus, the model established by the stepwise procedure 
comprised a set of predictors that had an important effect on the dependent variables, and that best explained the response according with the interactions being considered [34, 35]. During the modelling by the SRG method, the four experimental data at each temperature (obtained from the weight measurement of the four cylindrical aluminum plates) were employed in order to obtain a robust goodness model.

\section{Artificial neural networks}

ANNs are used to describe the relationship of temperature and drying time with water content, using a unique non-linear model. For this approach, the regression networks feed-forward and cascade-forward architectures with a hidden layer were considered. The training function Levenberg-Marquardt backpropagation (trainlm) and the transfer functions: hyperbolic-tangent (tansig, Equation 11), log-sigmoid (logsig, Equation 12), soft max (softmax, Equation 13) and radial basics (radbas, Equation 14) were assessed for each network architecture [36]. The number of hidden-layer neurons, which ranged from three to eight, were tested for each ANN.

$$
\begin{aligned}
& \operatorname{tansig}(n)=\frac{2}{[1+\exp (-2 n)]-1} \\
& \log \operatorname{sig}(n)=\frac{1}{[1+\exp (-n)]} \\
& \operatorname{softmax}(n)=\frac{\exp (n)}{\operatorname{sum}(\exp (n))} \\
& \operatorname{radbas}(n)=\exp \left(-n^{2}\right)
\end{aligned}
$$

Where $n$ is the matrix of net input (column) vectors.

The input and output data were divided into two subgroups, the first subgroup, corresponding to the four experimental data at each temperature, and the second subgroup, corresponding to the mean from the four experimental data at each temperature level. Thus, for each neural network, the number of neurons and transfer function used in the analysis, a loop of eight epochs was carried out in order to determine the best performance of neural network and best parameter conditions.

\section{Statistical validation}

For the three mathematical approaches, the adjusted determination coefficients " $R_{\text {adj }}^{2}$ (Equation15), the mean relative error "MRE, \%" (Equation 16) and mean square error " $m s e$, dimensionless" (Equation 17) were employed to evaluate how successful the model was based on the number of model parameters, the proximity between the experimental and calculated data, and the quality of an estimator or set of predictions in terms of their variation and degree of bias in the neural network or predicted model, respectively. Furthermore, the "regstats" function was used to observe the residual values between the experimental and calculated data and the "lillietest" function was used to determine if the residuals followed a normal distribution [23].

$$
\begin{aligned}
& R_{a d j}^{2}=1-\left(1-R^{2}\right) \frac{n-1}{n-m} \\
& M R E=\frac{100}{n} \sum_{n=1}^{\infty} \frac{\left|x_{i}^{*}-x_{i}\right|}{x_{i}} \\
& m s e=\frac{1}{n} \sum_{i=1}^{n}\left(x_{i}^{*}-x_{i}\right)^{2}
\end{aligned}
$$

In Eqs. (15) to (17), $x_{i}^{*}$ represents the experimental values; $x_{i}$ represents the estimated values; $n$ is the number of experimental values, $m$ is the number of estimated parameters and $R^{2}$ is the determination coefficient. A model with a MRE below $10 \%$ is considered to have good accuracy, and a model with a MRE between 10 and $15 \%$ is considered to be acceptable [37]. On the other hand, the mse is a risk function corresponding to the expected value of the squared error loss. Thus, mse is a quality measure of an estimator (it is always non-negative), where values closer to zero indicates a better result [36]. 


\section{RESULTS AND DISCUSSION}

\section{Experimental drying data}

Figure 1 shows the experimental water content " $X$ " at different drying times for both materials. The relative humidity of the dried air ranged from $10-43 \%$ and from $10-46 \%$, and the sample thicknesses determined in the experimental procedures were $1.035 \pm 0.298 \mathrm{~cm}$ and $1.290 \pm 0.168 \mathrm{~cm}$ for the shrimp shell and crab exoskeleton, respectively.

The water content $(X)$ of shrimp shells varied in ranges of $3.290-0.805 \mathrm{~kg} / \mathrm{kg}$, d.b., $3.290-0.151 \mathrm{~kg} / \mathrm{kg}$, d.b. and $3.290-0.805 \mathrm{~kg} / \mathrm{kg}$, d.b., corresponding to times of $0-21600 \mathrm{~s}$ and temperatures of 30,45 and 60 ${ }^{\circ} \mathrm{C}$, respectively. For the crab exoskeleton, the values for $X$ varied between $1.079-0.294 \mathrm{~kg} / \mathrm{kg}$, d.b., 1.079 $-0.099 \mathrm{~kg} / \mathrm{kg}$, d.b. and $1.079-0.114 \mathrm{~kg} / \mathrm{kg}$, d.b., obtained at times of $0-16200 \mathrm{~s}$ and temperatures of 30 , 45 and $60^{\circ} \mathrm{C}$, respectively. All the experimental data presented a decreasing rate period.

Time intervals taken to reach equilibrium were $18000 \mathrm{~s}, 16200 \mathrm{~s}$ and $13200 \mathrm{~s}$ for the shrimp shell and $13200 \mathrm{~s}, 9600 \mathrm{~s}$ and 7200 for the crab exoskeleton, corresponding to temperatures of 30,45 and $60{ }^{\circ} \mathrm{C}$, respectively. It was also observed that the curves at $60^{\circ} \mathrm{C}$ showed a more pronounced slope than the curves at $45^{\circ} \mathrm{C}$, that, in its turn, were more pronounced than the curves at $30^{\circ} \mathrm{C}$. This behavior could be associated with the chemical composition and physical structure of the materials. For the shrimp shell, the carbohydrate content of $28.004 \pm 1.963 \mathrm{~g} / 100 \mathrm{~g}$ w.b. and protein content of $39.107 \pm 1.791$ were observed, these being the components that could be interfering in the transport of water from the surface of the shrimp shell to the hot air. Shrimp shells contain chitin and chitosan, that can be obtained by chemical and enzymatic hydrolysis, and in both cases, the use of high temperatures in presence of a catalyzing media (ethanol or sodium peroxide) could improve the recovery of water-soluble chitosan [5, 38]. This solubilizes the carbohydrates, referring to chitin and chitosan, easing adsorption of water by the system, since the vapor pressure is reduced in the material [39, 40]. Studies carried out by Prachayawarakorn and coauthors [41] showed that at high temperatures, the drying rates are very high due to high water concentrations at the surface, thereby allowing the water to be removed easily. In addition, the drying rates decrease almost linearly with the moisture contents.

A
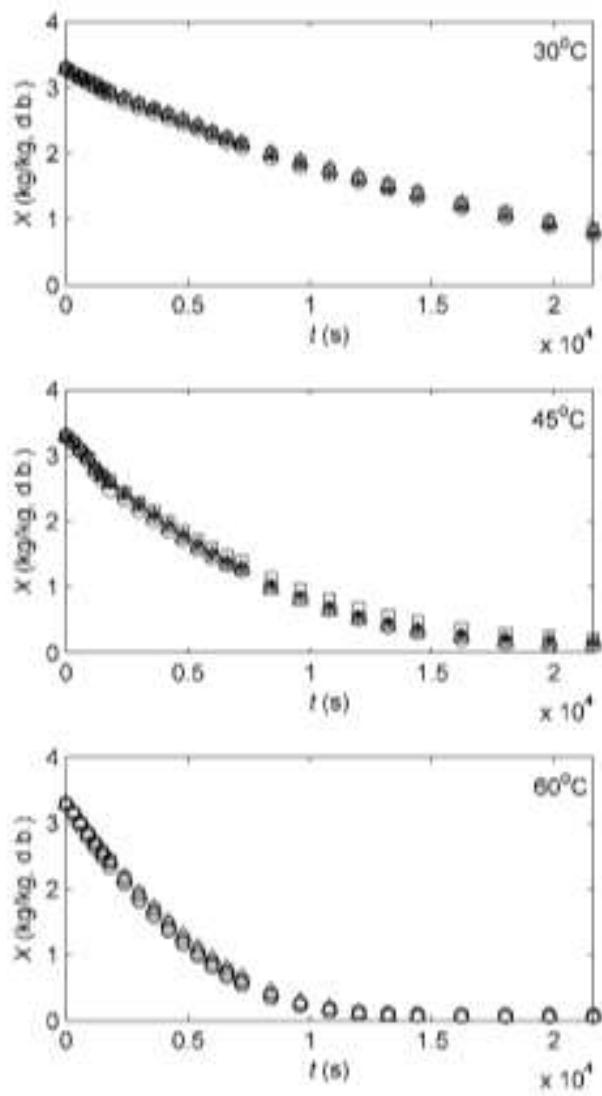

B
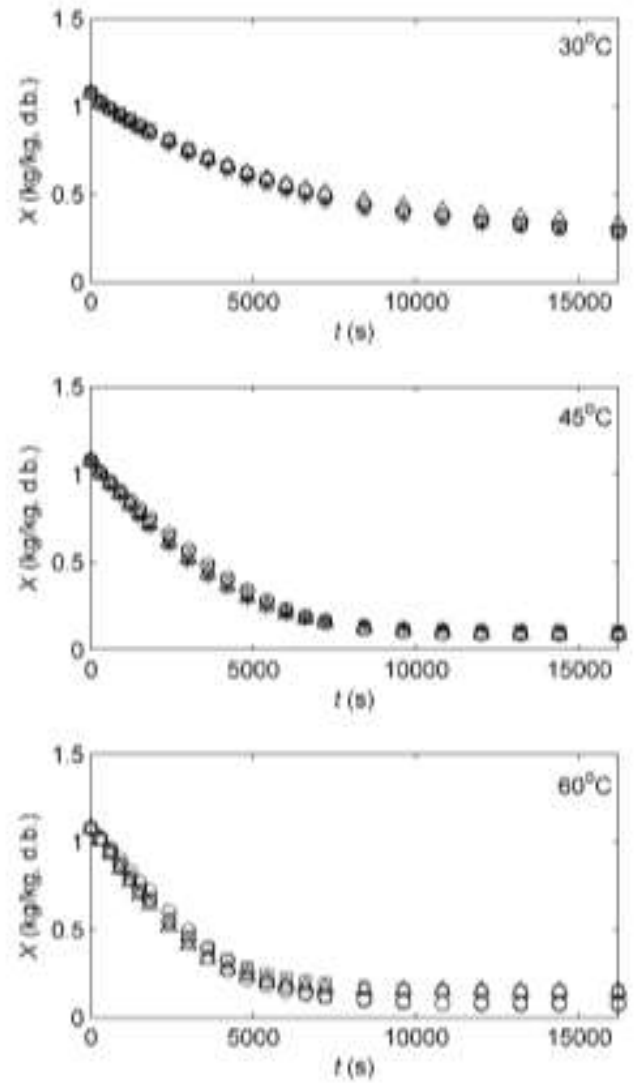

Figure 1. Drying kinetics curves for shrimp shell $(A)$ and crab exoskeleton $(B)$ at the different temperature levels. $(0)$ sample 1, $(\Delta)$ sample 2, (口) sample 3 and $(*)$ sample 4. 
In regard with crab exoskeleton, a high ash composition can be observed, around $58.638 \pm 0.271 \mathrm{~g} / 100 \mathrm{~g}$ w.b., characteristic of such materials, while the protein content can be attributed to collagen, which is soluble in water, and the essential amino acids [42]. The outer layer has a heavily calcified cuticle, with a significant amount of calcium carbonate being replaced by calcium phosphate [6]. Beneath the outer layer there is a fibrous and semipermeable region, responsible for the energy interactions. According to Chen and coauthors [43] the exoskeleton contains a microstructure with porous tubules and a ribbon shape that twists in a helical fashion, conferring stretch and high density. The width of a single tubule is about $1 \mu \mathrm{m}$ and the thickness is about $0.2 \mu \mathrm{m}$. The results revealed a gradient in the calcium content between the exocuticle and the endocuticle, indicating that the exocuticle is highly mineralized. Such design (great hardness and wear resistance on the surface) is important in order to understand the direct relationship between the drying temperature and the dehydration rate described above.

For both products, a drying time of $5 \mathrm{~h}$ in the minor temperature $\left(30^{\circ} \mathrm{C}\right)$ was effective to obtain a consistent dry product that can be used as raw material for industrial applications. Considering the long-term effect of the drying temperature on chemical composition, slightly higher degradation rates in shrimp shell were observed compared with crab exoskeleton, even if these do not affect the drying process of the product. Thus, in terms of processing, useful information was obtained, allowing selection of optimal drying conditions, as these can be applied to different drying methods, such as solar drying, which may be carried out at temperatures similar to the lowest temperature investigated in the present work $[8,9,44]$.

\section{Modelling with thin-layer models}

Table 2 shows the results obtained for the parameters used when employing the thin-layer models. 
Table 2. Results obtained for the parameters in the statistical validation of the thin-layer models.

\begin{tabular}{|c|c|c|c|c|c|c|c|}
\hline \multirow{2}{*}{ Model } & \multirow{2}{*}{ Parameter } & \multicolumn{3}{|c|}{ Shrimp shell } & \multicolumn{3}{|c|}{ Crab exoskeleton } \\
\hline & & $30^{\circ} \mathrm{C}$ & $45^{\circ} \mathrm{C}$ & $60^{\circ} \mathrm{C}$ & $30^{\circ} \mathrm{C}$ & $45^{\circ} \mathrm{C}$ & $60^{\circ} \mathrm{C}$ \\
\hline \multirow{5}{*}{ Weibull } & $k_{1}$ & 103 & 120 & 77 & 91.866 & 40.550 & 63.665 \\
\hline & $k_{2}$ & $6.535 \times 10^{-3}$ & $1.712 \times 10^{-2}$ & $1.696 \times 10^{-2}$ & $1.688 \times 10^{-2}$ & $1.241 \times 10^{-2}$ & $2.245 \times 10^{-2}$ \\
\hline & $R^{2}{ }_{a d j}$ & 0.998 & 0.997 & 0.995 & 0.994 & 0.993 & 0.994 \\
\hline & $M R E(\%)$ & 1.635 & 12.391 & 41.905 & 4.964 & 17.676 & 10.874 \\
\hline & mse & 0.026 & 0.059 & 0.109 & 0.024 & 0.037 & 0.029 \\
\hline \multirow{5}{*}{ Peleg } & $k_{1}$ & 4983 & 2099 & 1266 & 6080 & 3065 & 2476 \\
\hline & $k_{2}$ & 0.173 & 0.206 & 0.225 & 0.874 & 0.747 & 0.799 \\
\hline & $R^{2}{ }_{a d j}$ & 0.999 & 0.996 & 0.981 & 0.998 & 0.980 & 0.974 \\
\hline & $\operatorname{MRE}(\%)$ & 0.616 & 10.908 & 66.106 & 1.476 & 20.792 & 21.525 \\
\hline & mse & 0.013 & 0.047 & 0.139 & 0.007 & 0.042 & 0.048 \\
\hline \multirow{5}{*}{ Henderson-Pabis } & $k_{1}$ & 0.999 & 1.019 & 1.056 & 0.960 & 1.057 & 1.065 \\
\hline & $k_{2}$ & $6.312 \times 10^{-5}$ & $1.457 \times 10^{-4}$ & $2.353 \times 10^{-4}$ & $1.213 \times 10^{-4}$ & $3.259 \times 10^{-4}$ & $3.790 \times 10^{-4}$ \\
\hline & $R^{2} a d j$ & 0.998 & 0.996 & 0.992 & 0.992 & 0.991 & 0.993 \\
\hline & $\operatorname{MRE}(\%)$ & 1.634 & 11.027 & 34.594 & 3.757 & 15.430 & 8.214 \\
\hline & mse & 0.026 & 0.054 & 0.088 & 0.017 & 0.033 & 0.023 \\
\hline \multirow{6}{*}{ Logarithmic } & $k_{1}$ & 1.157 & 1.074 & 1.092 & 0.855 & 1.099 & 1.083 \\
\hline & $k_{2}$ & $4.919 \times 10^{-5}$ & $1.250 \times 10^{-4}$ & $2.100 \times 10^{-4}$ & $1.689 \times 10^{-4}$ & $2.817 \times 10^{-4}$ & $3.537 \times 10^{-4}$ \\
\hline & $k_{3}$ & -0.542 & -0.227 & -0.156 & 0.129 & -0.059 & -0.026 \\
\hline & $R^{2}{ }_{a d j}$ & 0.999 & 0.998 & 0.994 & 0.999 & 0.994 & 0.994 \\
\hline & $M R E(\%)$ & 0.519 & 5.481 & 30.356 & 0.528 & 9.884 & 8.163 \\
\hline & mse & 0.011 & 0.030 & 0.068 & 0.003 & 0.022 & 0.021 \\
\hline \multirow{5}{*}{ Wang and Sing } & $k_{1}$ & $9.989 \times 10^{-10}$ & $3.042 \times 10^{-9}$ & $4.864 \times 10^{-9}$ & $4.889 \times 10^{-9}$ & $8.772 \times 10^{-9}$ & $9.823 \times 10^{-9}$ \\
\hline & $k_{2}$ & $-5.657 \times 10^{-5}$ & $-1.087 \times 10^{-4}$ & $-1.455 \times 10^{-4}$ & $-1.192 \times 10^{-4}$ & $-1.965 \times 10^{-4}$ & $-2.097 \times 10^{-4}$ \\
\hline & $R^{2} a d j$ & 0.989 & 0.996 & 0.982 & 0.993 & 0.980 & 0.955 \\
\hline & MRE (\%) & 1.432 & 10.644 & 86.405 & 4.223 & 24.646 & 34.276 \\
\hline & mse & 0.027 & 0.061 & 0.137 & 0.022 & 0.043 & 0.065 \\
\hline \multirow{4}{*}{ Lewis } & $k_{1}$ & $6.322 \times 10^{-5}$ & $1.420 \times 10^{-4}$ & $2.204 \times 10^{-4}$ & $1.293 \times 10^{-4}$ & $3.061 \times 10^{-4}$ & $3.527 \times 10^{-4}$ \\
\hline & $R^{2}{ }_{a d j}$ & 0.998 & 0.997 & 0.994 & 0.995 & 0.994 & 0.995 \\
\hline & $\operatorname{MRE}(\%)$ & 1.635 & 12.391 & 41.905 & 4.964 & 17.676 & 10.874 \\
\hline & mse & 0.025 & 0.058 & 0.109 & 0.023 & 0.037 & 0.029 \\
\hline \multirow{5}{*}{ Page } & $k_{1}$ & $4.871 \times 10^{-5}$ & $5.978 \times 10^{-5}$ & $2.611 \times 10^{-5}$ & $4.644 \times 10^{-4}$ & $3.447 \times 10^{-5}$ & $4.484 \times 10^{-5}$ \\
\hline & $k_{2}$ & 1.028 & 1.098 & 1.252 & 0.854 & 1.267 & 1.258 \\
\hline & $R^{2}{ }_{a d j}$ & 0.998 & 0.998 & 0.998 & 0.997 & 0.997 & 0.999 \\
\hline & $M R E(\%)$ & 1.357 & 5.929 & 11.821 & 2.036 & 7.502 & 1.158 \\
\hline & mse & 0.024 & 0.037 & 0.036 & 0.009 & 0.015 & 0.004 \\
\hline \multirow{6}{*}{ Midilli } & $k_{1}$ & $1.151 \times 10^{-4}$ & $9.056 \times 10^{-5}$ & $2.963 \times 10^{-5}$ & $2.326 \times 10^{-4}$ & $4.398 \times 10^{-5}$ & $4.517 \times 10^{-5}$ \\
\hline & $k_{2}$ & 0.910 & 1.045 & 1.236 & 0.947 & 1.234 & 1.257 \\
\hline & $k_{3}$ & $-2.051 \times 10^{-5}$ & $-6.072 \times 10^{-6}$ & $-2.119 \times 10^{-6}$ & $5.158 \times 10^{-6}$ & $-1.751 \times 10^{-6}$ & $-5.542 \times 10^{-8}$ \\
\hline & $R^{2}{ }_{a d j}$ & 0.999 & 0.998 & 0.998 & 0.999 & 0.998 & 0.999 \\
\hline & $M R E(\%)$ & 0.437 & 4.953 & 13.128 & 0.576 & 4.411 & 1.257 \\
\hline & mse & 0.009 & 0.029 & 0.034 & 0.003 & 0.011 & 0.004 \\
\hline \multirow{7}{*}{ Two-terms } & $k_{1}$ & $9.639 \times 10^{-4}$ & $-2.489 \times 10^{-2}$ & $-7.895 \times 10^{-2}$ & 0.049 & -0.087 & -0.107 \\
\hline & $k_{2}$ & 0.994 & 0.993 & 0.993 & 0.993 & 0.993 & 0.993 \\
\hline & $k_{3}$ & 0.999 & 1.025 & 1.078 & 0.950 & 1.087 & 1.107 \\
\hline & $k_{4}$ & $6.311 \times 10^{-5}$ & $1.467 \times 10^{-4}$ & $2.412 \times 10^{-4}$ & $1.193 \times 10^{-4}$ & $3.367 \times 10^{-4}$ & $3.965 \times 10^{-4}$ \\
\hline & $R^{2}{ }_{a d j}$ & 0.998 & 0.996 & 0.993 & 0.992 & 0.991 & 0.996 \\
\hline & $M R E(\%)$ & 1.631 & 10.653 & 31.929 & 3.522 & 14.188 & 6.491 \\
\hline & mse & 0.025 & 0.053 & 0.078 & 0.016 & 0.029 & 0.017 \\
\hline \multirow{6}{*}{$\begin{array}{l}\text { Diffusion } \\
\text { approach }\end{array}$} & $k_{1}$ & 0.998 & 1.022 & 1.078 & 2.090 & 1.265 & 1.626 \\
\hline & $k_{2}$ & $6.312 \times 10^{-5}$ & $1.462 \times 10^{-4}$ & $2.208 \times 10^{-4}$ & $1.213 \times 10^{-4}$ & $2.311 \times 10^{-4}$ & $4.952 \times 10^{-4}$ \\
\hline & $k_{3}$ & 0.993 & 984 & -0.096 & 0.999 & 0.341 & 2.143 \\
\hline & $R^{2}$ adj & 0.998 & 0.996 & 0.994 & 0.992 & 0.994 & 0.999 \\
\hline & $\operatorname{MRE}(\%)$ & 1.634 & 10.862 & 27.966 & 3.757 & 10.419 & 1.944 \\
\hline & mse & 0.025 & 0.054 & 0.072 & 0.017 & 0.024 & 0.006 \\
\hline
\end{tabular}

$k_{1}, k_{2}, k_{3}$ and $k_{4}$ are the drying constant (s; $\mathbf{s}^{-1}$; dimensionless). mse: mean square error (dimensionless).

All the thin-layer models tested are key tools in time prediction needed to reach the desired water content, as well as in the scaling up of the process from laboratory to industrial capacity [10]. However, not all these models had a satisfactory statistical evaluation. For shrimp shell, the models of Page (with $R^{2}{ }_{\text {adj }}=0.998, M R E$ $<11.821 \%$ and $m s e<0.037$ ) and Midilli (with $R^{2}$ adj $>0.998, M R E<13.128 \%$ and $m s e<0.034$ ) were the best models to fit the experimental values. On the other hand, the models of Weibull, Logarithmic, Page, 
Midilli, Two-terms and the Diffusion approach were the best to fit the results of crab exoskeleton, the Midilli model showing the best statistical accuracy, with $R^{2}$ adj $>0.998, M R E<4.411 \%$ and $m s e<0.011$.

The thin-layer and monolayer empirical models are usually used for foodstuffs and rarely for Crustacea, but some studies concerning Crustacea were found in the literature, such as the drying kinetics for yellow squat lobster (Cervimunida jhoni) [19], the drying kinetics for shrimp [45, 46] and sorption isotherms for shrimp [41]. In addition, the drying curves of shrimp shell, for example, show a tendency for good accuracy when modelled at temperatures of 30 and $45^{\circ} \mathrm{C}$, showing poor accuracy at a temperature of $60^{\circ} \mathrm{C}$. Therefore the kinetic constants of the results did not show a linear tendency with respect to the temperature, making it difficult to use these models to find an Arrhenius-type relationship or even integrate their constants to relate them to a diffusive coefficient $[32,47]$.

Figure 2 shows the statistical performance between the experimental and calculated data for the best fitted models.
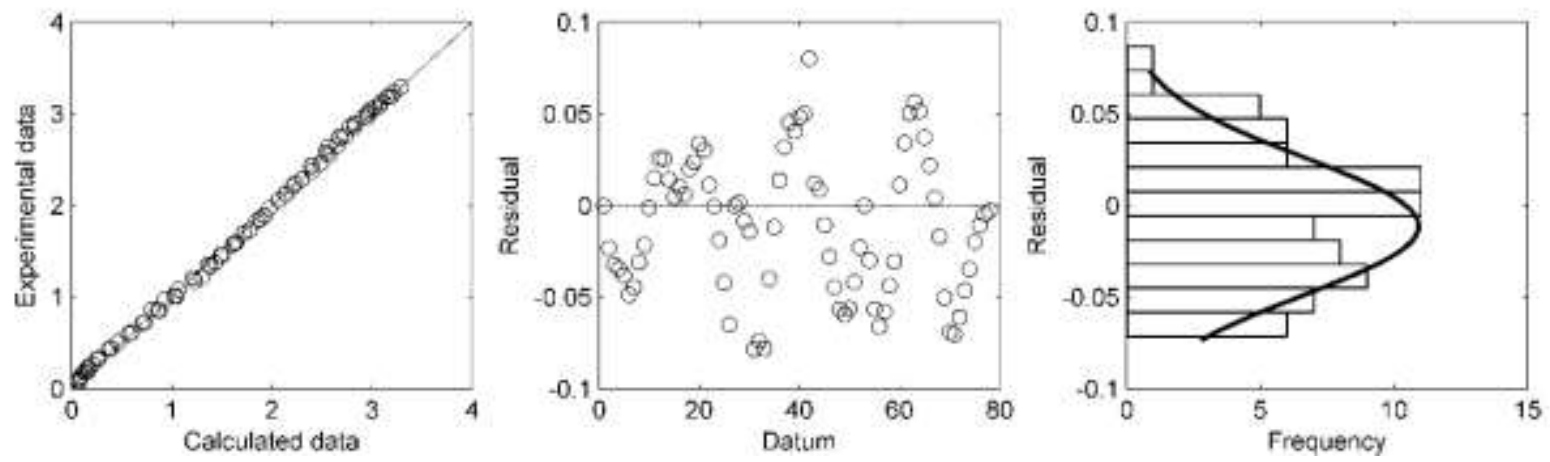

A
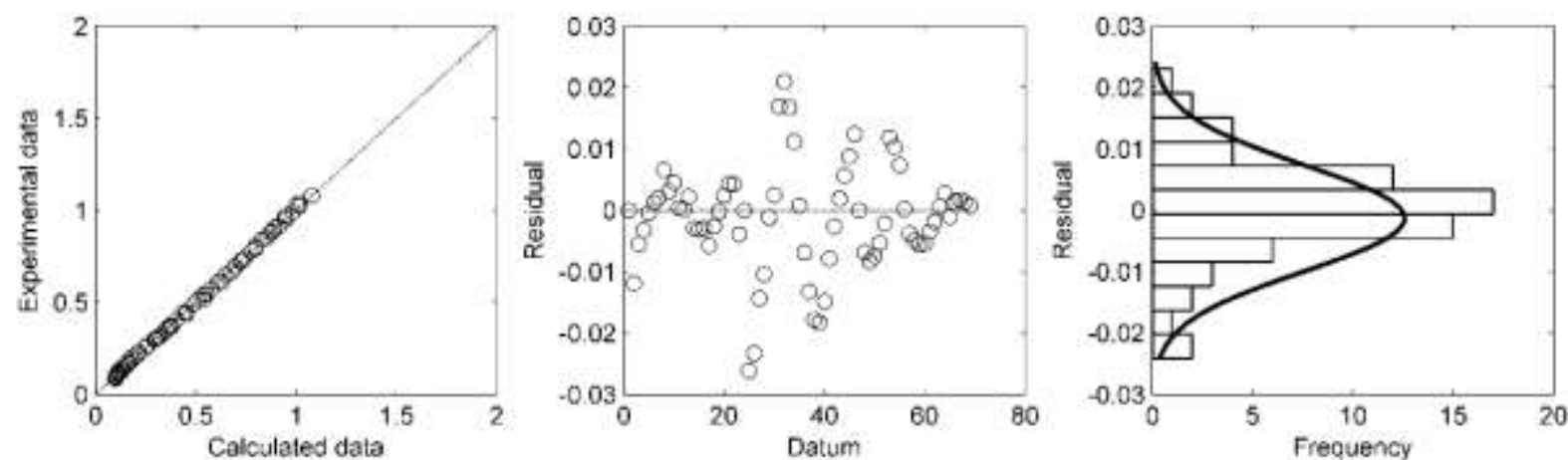

Figure 2. Residual analysis between the experimental and calculated drying curves using the best fitting models of Page for shrimp shell (A) and Midilli for crab exoskeleton (B).

\section{Modelling with the stepwise fit regression method}

To use the SRG method, four samples data of both materials were used, combining the factors of temperature $(T)$ and drying time $(t)$, showing 9 and 8 correlations, first order to third order, with the best performance for the $X$ responses for the shrimp shell and crab exoskeleton, respectively. Table 3 shows the results fitting of linear/quadratic interactive regression models, which were simple to construct but required large sets of experimental data. 
Table 3. Results obtained in the multi-nonlinear regression using the stepwise fit method.

\begin{tabular}{|c|c|c|c|c|c|c|}
\hline Material & Parameter & Value & $p<0.05$ & $R^{2}{ }_{a d j}$ & MRE (\%) & mse \\
\hline \multirow{9}{*}{ Shrimp shell } & Intercept & 3.463 & --- & \multirow{9}{*}{0.992} & \multirow{9}{*}{21.367} & \multirow{9}{*}{0.077} \\
\hline & $t^{2}$ & $1.876 \times 10^{-8}$ & $7.016 \times 10^{-72}$ & & & \\
\hline & $t \times T$ & $-1.068 \times 10^{-5}$ & $4.143 \times 10^{-72}$ & & & \\
\hline & $\exp (T)$ & $8.143 \times 10^{-28}$ & 0.029 & & & \\
\hline & $t^{3}$ & $-1.000 \times 10^{-12}$ & $3.502 \times 10^{-46}$ & & & \\
\hline & $T^{3}$ & $-1.872 \times 10^{-6}$ & $6.737 \times 10^{-12}$ & & & \\
\hline & $T^{2} x t^{3}$ & $-8.389 \times 10^{-17}$ & 0.001 & & & \\
\hline & $T \times t^{3}$ & $1.896 \times 10^{-14}$ & $7.145 \times 10^{-17}$ & & & \\
\hline & $t \times T^{3}$ & $8.289 \times 10^{-10}$ & $1.625 \times 10^{-41}$ & & & \\
\hline \multirow{8}{*}{ Crab exoskeleton } & Intercept & 1.144 & --- & \multirow{8}{*}{0.988} & \multirow{8}{*}{10.149} & \multirow{8}{*}{0.028} \\
\hline & $t^{2}$ & $1.727 \times 10^{-8}$ & $3.806 \times 10^{-96}$ & & & \\
\hline & $T^{2}$ & $-2.992 \times 10^{-5}$ & $1.149 \times 10^{-14}$ & & & \\
\hline & $t \times T$ & $-6.851 \times 10^{-6}$ & $8.775 \times 10^{-150}$ & & & \\
\hline & $t^{3}$ & $-1.402 \times 10^{-12}$ & $6.989 \times 10^{-74}$ & & & \\
\hline & $T^{2} \times t^{3}$ & $-3.602 \times 10^{-16}$ & $3.665 \times 10^{-39}$ & & & \\
\hline & $T \times t^{3}$ & $3.820 \times 10^{-14}$ & $7.191 \times 10^{-53}$ & & & \\
\hline & $t \times T^{3}$ & $8.496 \times 10^{-8}$ & $4.191 \times 10^{-97}$ & & & \\
\hline
\end{tabular}

--- (not apply), $t$ : is the time (s), $T$ : is the temperature $\left({ }^{\circ} \mathrm{C}\right)$ and $p$ : is the probability of the factor $F$. mse: mean square error (dimensionless).

Table 3 shows that values of $R^{2}{ }_{a d j}=0.992, M R E=21.367 \%$ and $m s e=0.077$ were obtained for shrimp shell, and of $R_{a d j}^{2}=0.988, M R E=10.149 \%$ and $m s e=0.028$ for crab exoskeleton. Thus, the statistical results for the responses of $X$ can only be considered suitable for the shrimp shell, the value for MRE obtained in the model for the crab exoskeleton being too high. Once again, the experimental data obtained at the temperature of $60{ }^{\circ} \mathrm{C}$ produced a non-linear tendency, resulting in low accuracy of the fitted model, as can be seen in Figure 3A. Even so, the use of parameters with coefficients to an order equal to 3 to build the interactive models lead to a good statistical performance, not producing overestimated results for the responses of $X$.
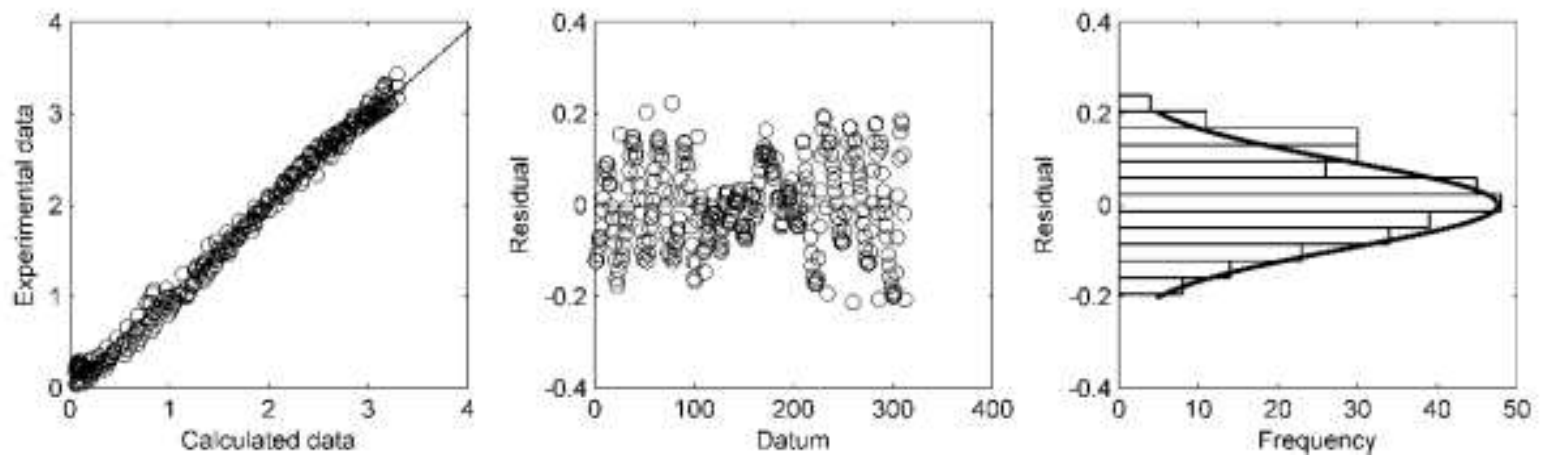

A
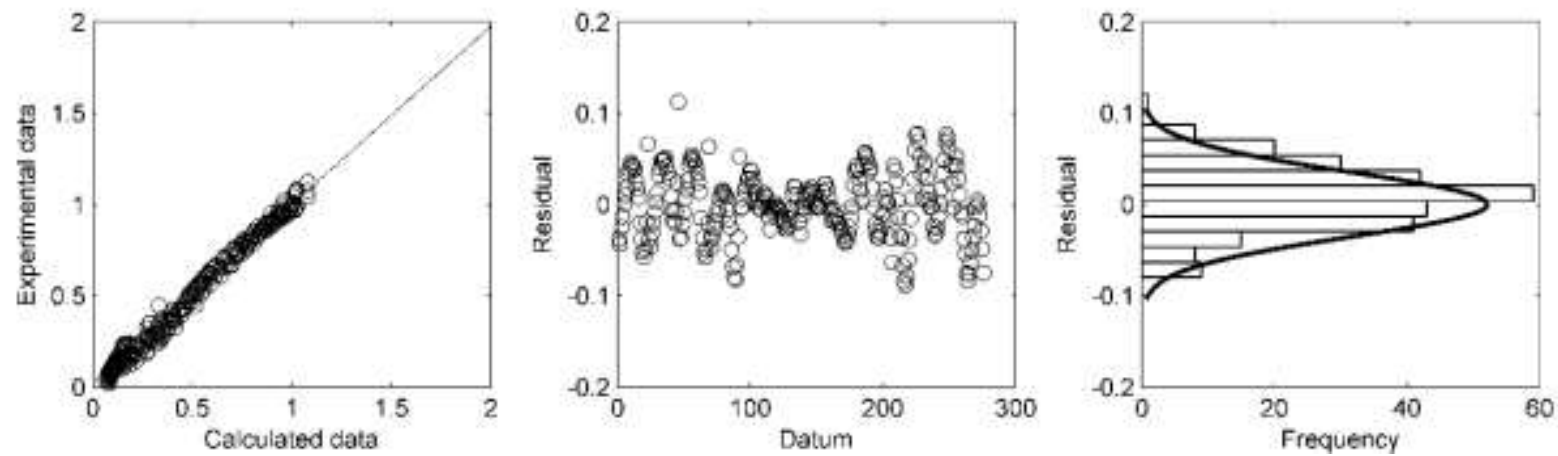

Figure 3. Residual analysis between the experimental and calculated drying curves for shrimp shell (A) and crab exoskeleton (B) using the stepwise fit regression models.

In general terms, the use of this method to model the drying kinetics of agricultural or maritime wastes should be more explored, since a single model can be obtained as a function of multiple variables produced in a drying process, e.g. hot air velocity, relative humidity at the entrance and exit of the equipment, and the 
drying temperature, amongst others. Some studies applied to microwave and air drying processes [25], biological processes [48], to the identification of acoustic fields in lignocellulose biomass [24] and the production of total and reducing sugars [36] pre-treated with power ultrasound, explored the SRG method and obtained well-fitting models. Thus, in the present research, the use of fitting methodologies such as SRG and ANNs was recommended to describe the behavior of the water content as a function of the temperature and drying time.

\section{Modelling with ANN}

Table 4 shows the results obtained for the performance of ANN as well as the statistical validation.

The results above show good statistical validation for both ANN architectures employed, since, for the shrimp shell, the transfer function "tansig" with six neurons in the hidden layer presented the best evaluations for the feed-forward network $\left(R_{\text {adj }}^{2}=0.998, M R E=3.516 \%\right.$ and $\left.m s e=0.023\right)$ and the cascade-forward network $\left(R_{\text {adj }}^{2}=0.998, M R E=3.347 \%\right.$ and $\left.m s e=0.023\right)$. Similarly, for the crab exoskeleton the transfer function "tansig" with four neurons in the hidden layer also presented the best evaluations for the feed-forward network $\left(R_{\text {adj }}^{2}=0.996, M R E=5.848 \%\right.$ and $\left.m s e=0.013\right)$ and the cascade-forward network $\left(R_{\text {adj }}^{2}=0.996\right.$, $M R E=5.840 \%$ and $m s e=0.013)$. In the modelling procedure, the tansig transfer function converged into 8 epochs. The selection of six and four neurons in the hidden layers to obtain the best results for both materials and neural networks was determined in the tests, to avoid the overestimated parameters observed with five, seven and eight neurons. Thus, the feed-forward and cascade-forward networks can be employed to simulate the drying kinetic curves of the shrimp shell and crab exoskeleton in the temperatures range from 30 to 60 ${ }^{\circ} \mathrm{C}$. Figure 4 shows the architectures with the best modelling parameters for the feed-forward and cascadeforward networks, and Figure 5 the statistical performances of the modelling.

Table 4. Best results and statistical validation of the neural network analysis.

\begin{tabular}{|c|c|c|c|c|c|c|c|}
\hline Material & ANN & $\begin{array}{l}\text { Transfer } \\
\text { function }\end{array}$ & Neurons & $\begin{array}{l}\text { Number of } \\
\text { parameters }\end{array}$ & $\boldsymbol{R}^{2}{ }_{a d j}$ & $\begin{array}{c}\text { MRE } \\
(\%)\end{array}$ & mse \\
\hline \multirow{8}{*}{ Shrimp shell } & \multirow{4}{*}{$\begin{array}{l}\text { Feed- } \\
\text { forward }\end{array}$} & tansig & 6 & 25 & 0.998 & 3.516 & 0.023 \\
\hline & & softmax & 7 & 29 & 0.998 & 3.321 & 0.023 \\
\hline & & logsig & 8 & 33 & 0.998 & 3.300 & 0.022 \\
\hline & & radbas & 8 & 33 & 0.998 & 3.356 & 0.023 \\
\hline & \multirow{4}{*}{$\begin{array}{l}\text { Cascade- } \\
\text { forward }\end{array}$} & tansig & 6 & 27 & 0.998 & 3.347 & 0.023 \\
\hline & & softmax & 7 & 31 & 0.998 & 3.399 & 0.023 \\
\hline & & logsig & 7 & 31 & 0.998 & 3.345 & 0.023 \\
\hline & & radbas & 7 & 31 & 0.998 & 3.306 & 0.023 \\
\hline \multirow{8}{*}{ Crab exoskeleton } & \multirow{4}{*}{$\begin{array}{l}\text { Feed- } \\
\text { forward }\end{array}$} & tansig & 4 & 17 & 0.996 & 5.848 & 0.013 \\
\hline & & softmax & 5 & 21 & 0.996 & 5.891 & 0.013 \\
\hline & & logsig & 5 & 21 & 0.996 & 5.836 & 0.013 \\
\hline & & radbas & 5 & 21 & 0.996 & 5.887 & 0.013 \\
\hline & \multirow{4}{*}{$\begin{array}{l}\text { Cascade- } \\
\text { forward }\end{array}$} & tansig & 4 & 19 & 0.996 & 5.840 & 0.013 \\
\hline & & softmax & 5 & 23 & 0.996 & 5.849 & 0.013 \\
\hline & & logsig & 4 & 19 & 0.996 & 5.924 & 0.013 \\
\hline & & radbas & 4 & 19 & 0.996 & 5.922 & 0.013 \\
\hline
\end{tabular}

mse: mean square error (dimensionless). 
A
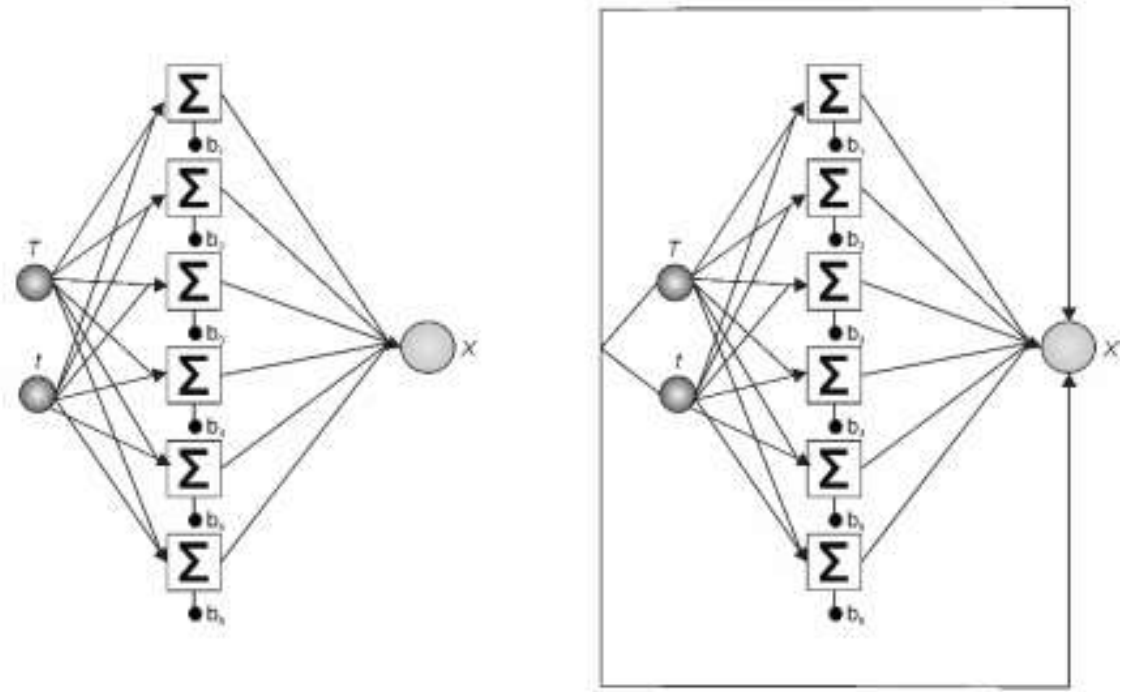

B
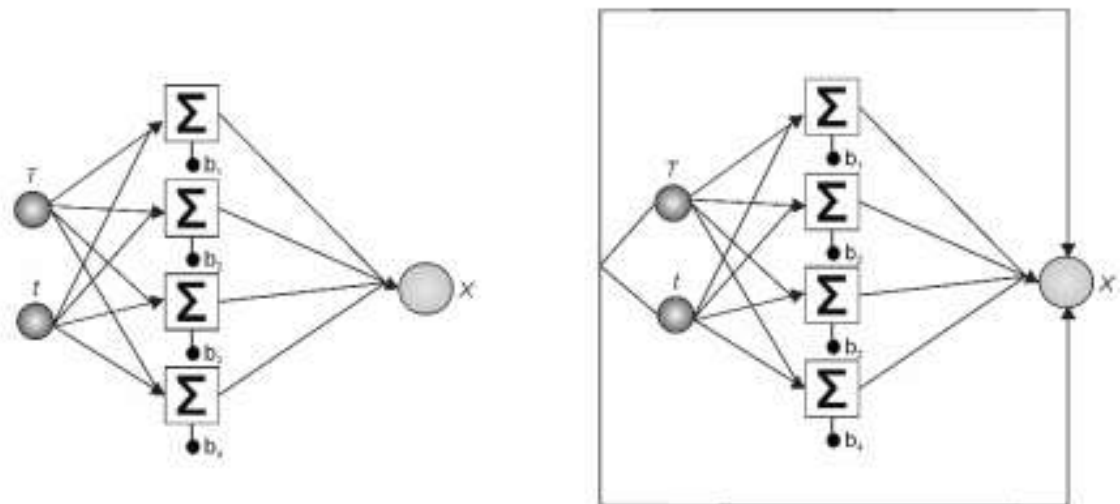

Figure 4. Architectures of the best ANNs for the simulations of the drying kinetics of shrimp shell (A) and crab exoskeleton (B).
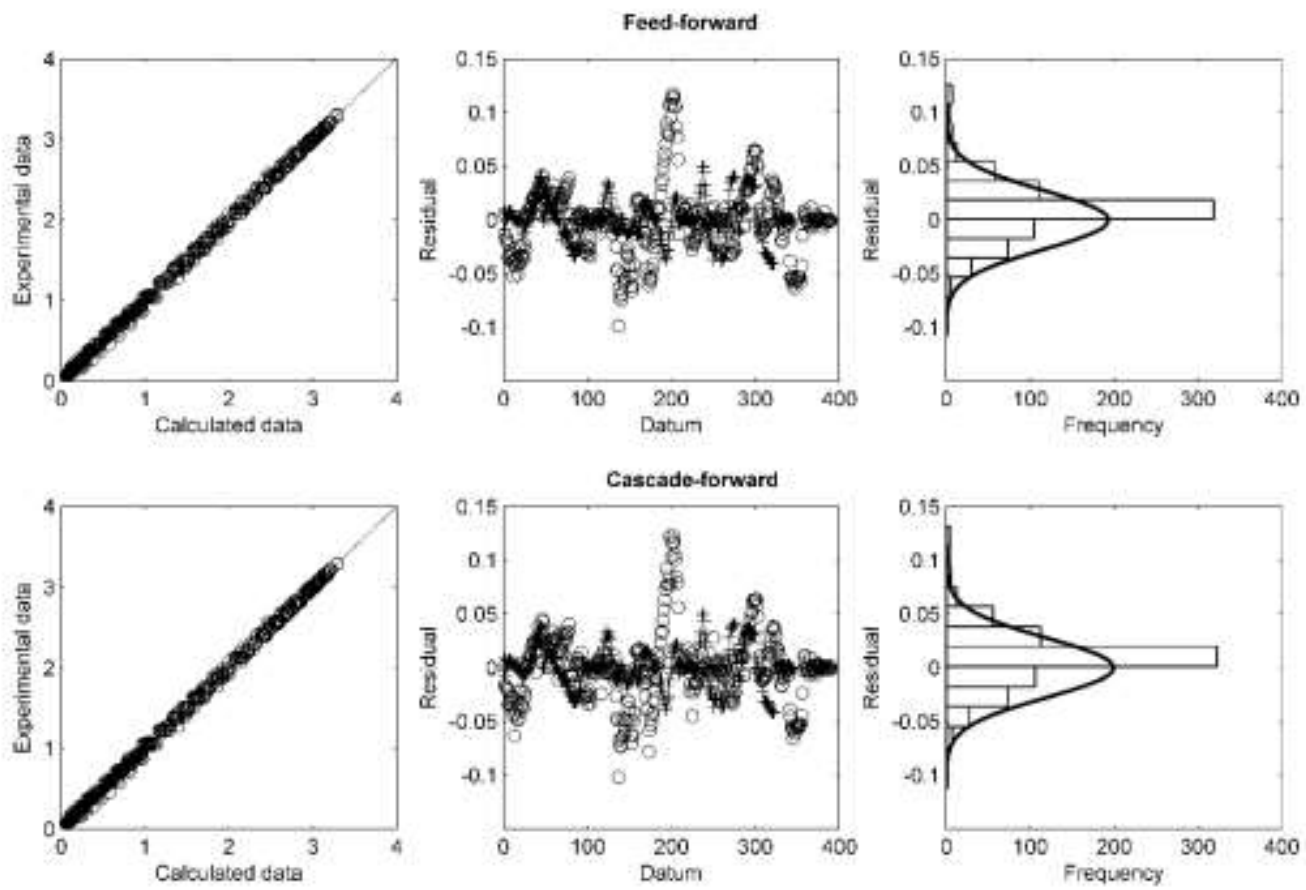

Figure 5. Residual analysis between the experimental and calculated drying curves for shrimp shell ( $($ ) and exoskeleton crab (+) using the best ANN architectures. 
Mathematical models for the feed-forward and cascade-forward architectures were obtained from Figure 4 as shown in Equations. (18) and (19) respectively:

$$
\begin{aligned}
& f_{(X)}=\psi\left[\left(\sum_{i, k=1}^{n} \varphi_{i} \omega_{i k}+\delta_{k}\right)+\sum_{j, k=1}^{n} \omega_{j k}^{l}\right] \\
& f_{(X)}=\sum_{i, j=1}^{n} \omega_{i j}^{0}+\psi\left[\left(\sum_{i, k=1}^{n} \varphi_{i} \omega_{i k}+\delta_{k}\right)+\sum_{j, k=1}^{n} \omega_{j k}^{l}\right]+\delta_{j}
\end{aligned}
$$

Where $\omega^{0}{ }_{i j}$ are the weights of the product between the inputs $(I)$ and outputs $(j)$ of the network, $\varphi_{i}$ are the inputs of the network, $\omega_{i k}$ are the weights of the product between the inputs and neurons of the hidden layer, $\delta_{k}$ are the biases of the neurons in the hidden layer, $\omega^{1}{ }_{j k}$ are the weights of the product between the neurons of the hidden layer and the outputs of the network, $\delta_{j}$ is the bias of the output network and $\psi$ is the tansig transfer function $\left[2 /\left(1+\exp \left(-2 \alpha_{j}\right)\right)+1\right][36,49]$.

The cascade-forward neural network was reported for use in the vapor-liquid equilibrium of binary mixtures [49], in oil extraction by supercritical fluids in a packed bed [50], in complex-images analyses [51] and in the hydrolysis of biomass with high intensity ultrasound [36], providing the modelling for complex relationships, especially for complex values, that can be investigated without complicated equations. On the other hand, the feed-forward network was employed in the modelling and control of the drying process of grape [22], in the prediction of the drying kinetics of carrot cubes during fluidized bed drying [11], and in the simulation of the drying of seedy grape [52] and tomato [53], since this architecture has been the most used by researchers in the simulation of drying process. When comparing the SRG method with the ANN method, the ANNs show better predictive power for complex behaviors than the stepwise regression models, although both methods have hardly been used in the field of modelling and simulation of the drying process. Lastly, the predictive power of the ANNs is reflected in the statistical evaluation itself, through the results of MRE (less than 10\%) and $m s e$ (close to 0 ), indicating a strong proximity between the simulated values and experimental data, as shown in Figure 6.

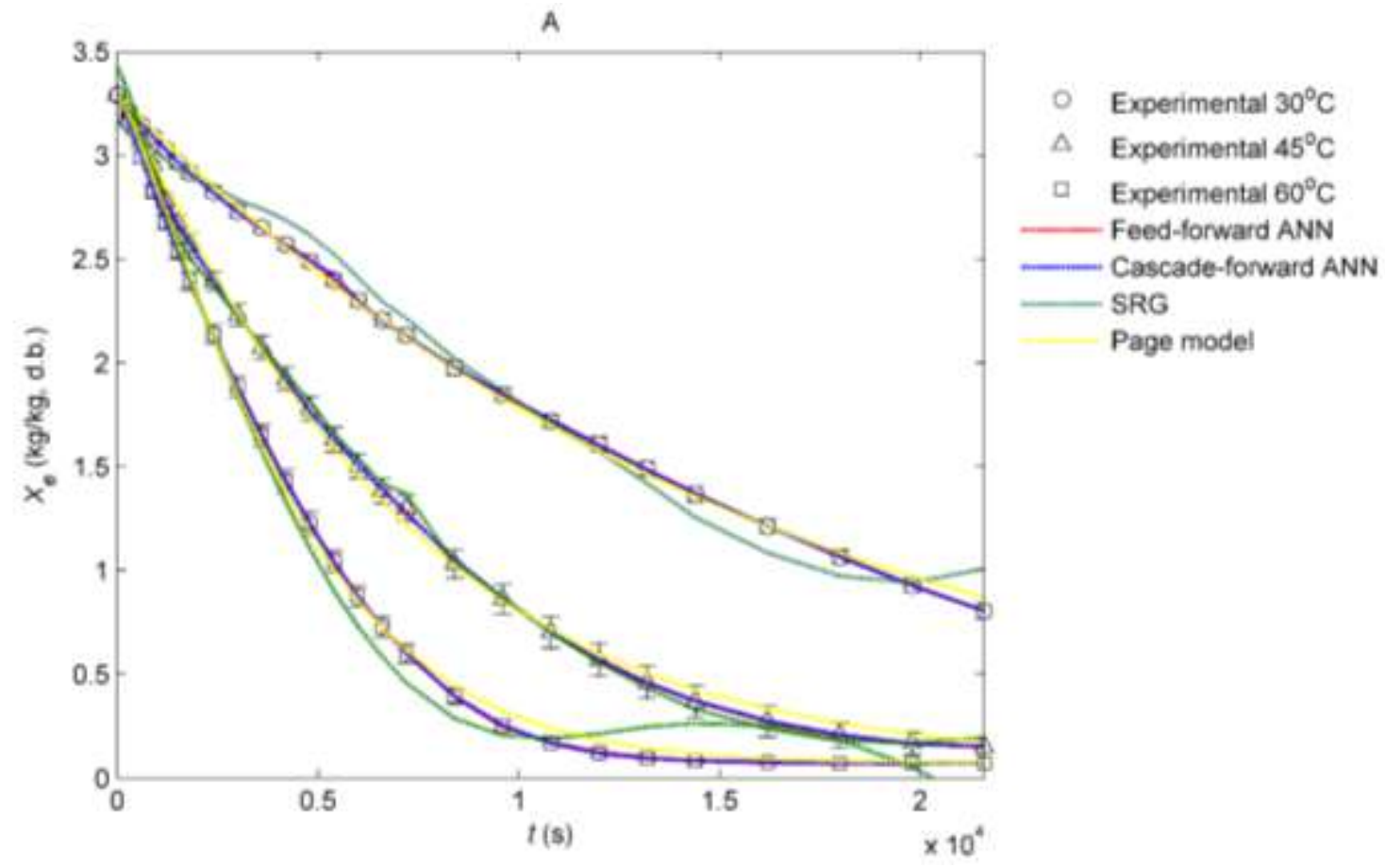


B

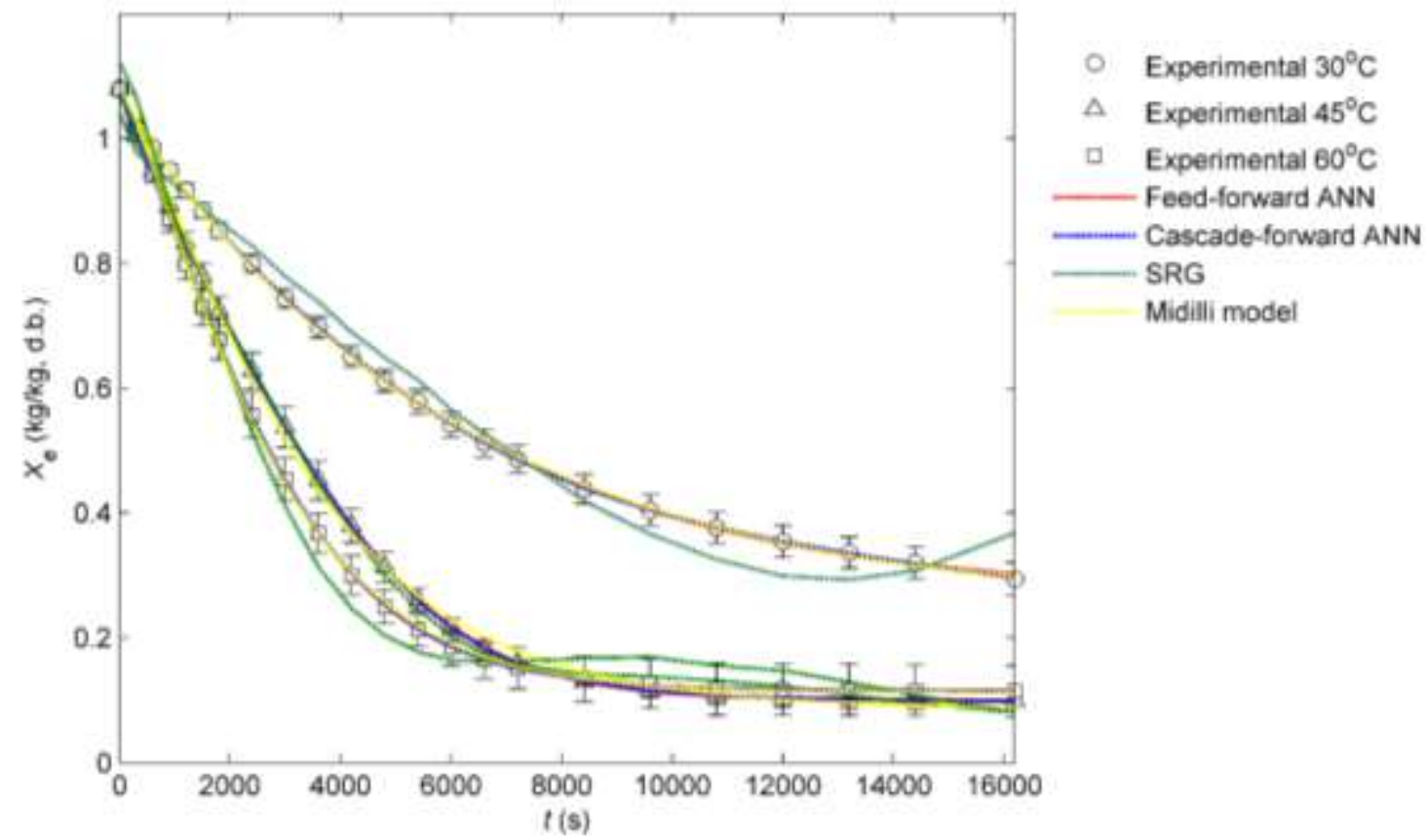

Figure 6. Comparison between the ANNs, SRG and thin-layer methods on the modelling of the drying rates of the shrimp shell $(A)$ and crab exoskeleton (B).

\section{CONCLUSIONS}

In the present study, the thin-layer drying kinetics of shrimp shell and crab exoskeleton were investigated experimentally, and a relationship determined between drying time (shortening) as drying temperature increased. Also, all the experimental drying kinetic curves showed a decreasing rate period. Thin-layer models, stepwise fit regression (SRG) and artificial neural networks (ANNs) were employed successfully in the modelling of the drying kinetics. For this purpose, the modelling with thin-layer models was carried out for each temperature, whereas the SRG and ANN were optimized for the whole temperature range of the study. In terms of accuracy, the trained recurrent ANN models were validated with experimental data and found to attain higher predictive quality than the stepwise fit regression method and thin-layer models. The ANN architectures developed and the subsequent models could be used to determine the appropriate drying conditions to reach the optimal energy efficiency in convective drying. Moreover, thin-layer models with theoretical parameters as a function of the temperature, e.g. the diffusion coefficient, could be employed to model the drying kinetics of shrimp shell and crab exoskeleton with greater accuracy. Finally, modelling with the SRG and ANNs methods could be applied to other products as well.

Acknowledgements: the authors are grateful to the Maranhão Foundation for the Protection of Research and Scientific and Technological Development (FAPEMA) for the financial support received in the form of a junior scholarship (process number BEX-007/17, Notice 23/2016) and to finance the research project (process number AQUIPESCA-06469/16).

\section{REFERENCES}

1. Yen M-T, Yang J-H, Mau J-L. Physicochemical characterization of chitin and chitosan from crab shells. Carbohydr Polym. 2009;75(1):15-21.

2. Raya I, Mayasari E, Yahya A, Syahrul M, Latunra Al. Shynthesis and characterizations of calcium hydroxyapatite derived from crabs shells (Portunus pelagicus) and its potency in safeguard agains to dental demineralizations. Int J Biomater. 2015:1-8.

3. Ahmed SH, El Sheikh EM, Morsy AMA. Potentiality of uranium biosorption from nitric acid solutions using shrimp shells. J Environ Radioact. 2014;134:120-7.

4. Mohanasrinivasan V, Mishra M, Paliwal JS, Singh SK, Selvarajan E, Suganthi V, Subathra Devi C. Studies on heavy metal removal efficiency and antibacterial activity of chitosan prepared from shrimp shell waste. Biotech. 2014;4(2):167-75.

5. Benhabiles MS, Salah R, Lounici H, Drouiche N, Goosen MFA, Mameri N. Antibacterial activity of chitin, chitosan and its oligomers prepared from shrimp shell waste. Food Hydrocoll. 2012;29(1):48-56. 
6. Cartwright JHE, Checa AG, Gale JD, Gebauer D, Sainz-Díaz CI. Calcium Carbonate Polyamorphism and Its Role in Biomineralization: How Many Amorphous Calcium Carbonates Are There? Angew Chem Inter Ed,. 2012;51(48):11960-70.

7. Devahastin S, Niamnuy C. Invited review: Modelling quality changes of fruits and vegetables during drying: a review. Int J Food Sci Technol. 2010;45(9):1755-67.

8. Prakash O, Kumar A. Solar greenhouse drying: A review. Renew Sust Energ Rev. 2014;29:905-10.

9. Lingayat A, Chandramohan VP, Raju VRK. Design, Development and Performance of Indirect Type Solar Dryer for Banana Drying. Energ Procedia. 2017;109:409-16.

10. Bialik M, Gondek E, Wiktor A, Latocha P, Witrowa-Rajachert. Mathematical modeling of Actinidia rguta (kiwiberry) drying kinetics. Agri Engineer. 2017;21(4):5-13.

11. Nazghelichi T, Aghbashlo M, Kianmehr MH, Omid M. Prediction of Energy and Exergy of Carrot Cubes in a Fluidized Bed Dryer by Artificial Neural Networks. Drying Technol. 2011;29(3):295-307.

12. Purschke B, Brüggen $\mathrm{H}$, Scheibelberger $\mathrm{R}$, Jäger $\mathrm{H}$. Effect of pre-treatment and drying method on physico-chemical properties and dry fractionation behaviour of mealworm larvae (Tenebrio molitor L.). Eur Food Res Technol. 2018;244(2):269-80.

13. Soysal $Y$, Ayhan Z, Eştürk O, Arıkan MF. Intermittent microwave-convective drying of red pepper: Drying kinetics, physical (colour and texture) and sensory quality. Biosyst Eng. 2009;103(4):455-63.

14. Santacatalina JV, Fissore D, Cárcel JA, Mulet A, García-Pérez JV. Model-based investigation into atmospheric freeze drying assisted by power ultrasound. J Food Eng. 2015;151:7-15.

15. Barba FJ, Parniakov O, Pereira SA, Wiktor A, Grimi N, Boussetta N, Saraiva JA, Raso J, Martin-Belloso O, WitrowaRajchert D, Lebovka N, et al. Current applications and new opportunities for the use of pulsed electric fields in food science and industry. Food Res Int. 2015;77:773-98.

16. Wiktor A, Iwaniuk M, Śledź M, Nowacka M, Chudoba T, Witrowa-Rajchert D. Drying Kinetics of Apple Tissue Treated by Pulsed Electric Field. Drying Technol. 2013;31(1):112-9.

17. Wu X, Liu Y, Li X, Wen P, Zhang Y, Long Y, Wang X, Guo Y, Xing F, Gao J. Preparation of aligned porous gelatin scaffolds by unidirectional freeze-drying method. Acta Biomater. 2010;6(3):1167-77.

18. Menlik T, Özdemir MB, Kirmaci V. Determination of freeze-drying behaviors of apples by artificial neural network. Expert Syst Appl. 2010;37(12):7669-77.

19. Vega-Gálvez A, Andrés A, Gonzalez E, Notte-Cuello E, Chacana M, Lemus-Mondaca R. Mathematical modelling on the drying process of yellow squat lobster (Cervimunida jhoni) fishery waste for animal feed. Anim Feed Sci Tech. 2009;151(3):268-79.

20. Nuñez-Mancilla Y, Perez-Won M, Vega-Gálvez A, Arias V, Tabilo-Munizaga G, Briones-Labarca V, LemusMondaca R, Di Scala K. Modeling mass transfer during osmotic dehydration of strawberries under high hydrostatic pressure conditions. Innov Food Sci Emerg Technol. 2011;12(3):338-43.

21. Vega-Gálvez A, Miranda M, Díaz LP, Lopez L, Rodriguez K, Di Scala K. Effective moisture diffusivity determination and mathematical modelling of the drying curves of the olive-waste cake. Bioresour Technol. 2010;101(19):726570 .

22. Khazaei NB, Tavakoli T, Ghassemian H, Khoshtaghaza MH, Banakar A. Applied machine vision and artificial neural network for modeling and controlling of the grape drying process. Comput Electron Agric. 2013;98:205-13.

23. Villa-Vélez HA, Váquiro HA, Lopes-Filho JF, Telis VRN, Telis-Romero J. Study of the specific heat capacity of biomass from banana waste for application in the second-generation ethanol industry. Environ Prog Sustain Energy. 2015;34(4):1221-8.

24. Villa-Vélez HA, Cornelio ML, Corrêa JLG, Telis-Romero J. Identification of acoustic fields in aqueous biomass solutions of banana waste pretreated by power ultrasound. Biomass Convers Biorefin. 2018;8(1):1-10.

25. Khraisheh MAM, McMinn WAM, Magee TRA. A multiple regression approach to the combined microwave and air drying process. J Food Eng. 2000;43(4):243-50.

26. AOAC. Official methods of analysis Gaithersburg: AOAC International; 2007.

27. Midilli A, Kucuk H, Yapar Z. A new model for single-layer drying. Drying Technol. 2002;20(7):1503-13.

28. Henderson SM. Progress in Developing the Thin Layer Drying Equation. Transactions of the ASAE. 1974;17(6):1167.

29. Yagcioglu A. Drying characteristic of laurel leaves under different conditions. Proceedings of the $7^{\text {th }}$ International congress on agricultural mechanization and energy, 1999. 1999:565-9.

30. Mujumdar AS. Handbook of industrial drying. New York: Marcel Dekker; 1987.

31. Perré P. The Proper Use of Mass Diffusion Equations in Drying Modeling: Introducing the Drying Intensity Number. Drying Technol. 2015;33(15-16):1949-62. 
32. Corzo O, Bracho N, Pereira A, Vásquez A. Weibull distribution for modeling air drying of coroba slices. LWT - Food Sci Tecnhol. 2008;41(10):2023-8.

33. Sarimeseli A. Microwave drying characteristics of coriander (Coriandrum sativum L.) leaves. Energ Convers Manage. 2011;52(2):1449-53.

34. Cevik A. Unified formulation for web crippling strength of cold-formed steel sheeting using stepwise regression. J Constr Steel Res. 2007;63(10):1305-16.

35. Chen Y, Shi R, Shu S, Gao W. Ensemble and enhanced PM10 concentration forecast model based on stepwise regression and wavelet analysis. Atmos Environ. 2013;74:346-59.

36. Villa-Vélez HA, Váquiro HA, Telis-Romero J. The effect of power-ultrasound on the pretreatment of acidified aqueous solutions of banana flower-stalk: Structural, chemical and statistical analysis. Ind Crops Prod. 2015;66:5261.

37. Sablani SS, Baik O-D, Marcotte M. Neural networks for predicting thermal conductivity of bakery products. J Food Eng. 2002;52(3):299-304.

38. Du Y, Zhao Y, Dai S, Yang B. Preparation of water-soluble chitosan from shrimp shell and its antibacterial activity. Innov Food Sci Emerg Technol. 2009;10(1):103-7.

39. Juang R-S, Wu F-C, Tseng R-L. Solute adsorption and enzyme immobilization on chitosan beads prepared from shrimp shell wastes. Bioresour Technol. 2001;80(3):187-93.

40. Niamnuy C, Devahastin S, Soponronnarit S, Vijaya Raghavan GS. Kinetics of astaxanthin degradation and color changes of dried shrimp during storage. J Food Eng. 2008;87(4):591-600.

41. Prachayawarakorn S, Soponronnarit $S$, Wetchacama $S$, Jaisut D. Desorption isotherms and drying characteristics of shrimp in superheated steam and hot air. Drying Technol. 2002;20(3):669-84.

42. Asunción Lage-Yusty M, Vilasoa-Martínez M, Álvarez-Pérez S, López-Hernández J. Chemical composition of snow crab shells (Chionoecetes opilio) Composición química del caparazón del cangrejo de las nieves (Chionoecetes opilio). CyTA - J Food. 2011;9(4):265-70.

43. Chen P-Y, Lin AY-M, McKittrick J, Meyers MA. Structure and mechanical properties of crab exoskeletons. Acta Biomater. 2008;4(3):587-96.

44. Belessiotis V, Delyannis E. Solar drying. Solar Energy. 2011;85(8):1665-91.

45. Namsanguan $Y$, Tia W, Devahastin S, Soponronnarit S. Drying Kinetics and Quality of Shrimp Undergoing Different Two-Stage Drying Processes. Drying Technol. 2004;22(4):759-78.

46. Tapaneyasin R, Devahastin S, Tansakul A. Drying methods and quality of shrimp dried in a jet-spouted bed dryer. J Food Process Eng. 2005;28(1):35-52.

47. Suherman, Peglow M, Tsotsas E. On the Applicability of Normalization for Drying Kinetics. Drying Technol. 2007;26(1):90-6.

48. Goodenough AE, Hart AG, Stafford R. Regression with Empirical Variable Selection: Description of a New Method and Application to Ecological Datasets. Plos One. 2012;7(3):e34338.

49. Lashkarbolooki M, Vaferi B, Shariati A, Zeinolabedini Hezave A. Investigating vapor-liquid equilibria of binary mixtures containing supercritical or near-critical carbon dioxide and a cyclic compound using cascade neural network. Fluid Phase Equilib. 2013;343:24-9.

50. Lashkarbolooki M, Shafipour ZS, Hezave AZ. Trainable cascade-forward back-propagation network modeling of spearmint oil extraction in a packed bed using SC-CO2. J Supercrit Fluid. 2013;73:108-15.

51. Narad S, Chavan P. Cascade Forward Back-propagation Neural Network Based Group Authentication Using $(n, n)$ Secret Sharing Scheme. Procedia Comput Sci. 2016;78:185-91.

52. Çakmak G, Yıldız C. The prediction of seedy grape drying rate using a neural network method. Comput Electron Agric. 2011;75(1):132-8.

53. Movagharnejad K, Nikzad M. Modeling of tomato drying using artificial neural network. Comput Electron Agric. 2007;59(1):78-85.

2021 by the authors. Submitted for possible open access publication under the terms and conditions of the Creative Commons Attribution (CC BY NC) license (https://creativecommons.org/licenses/by-nc/4.0/). 